ORIGINAL ARTICLE

\title{
Role of Arthoscopy in Knee Osteoarthritis Treatment
}

\author{
MUHAMMAD KHIZER HAYAT MAKKI ${ }^{1}$, SHAHID MEHMOOD ${ }^{2}$, MUHAMMAD IQBAL BUZDAR ${ }^{3}$, AISHA AJMAL $^{4}$, HAFIZ \\ MUHAMMAD AHMAD QURESHI ${ }^{5}$, MUHAMMAD ALI ${ }^{6}$ \\ ${ }^{1}$ Medical Officer, Bahawal Victoria Hospital Bahawalpur/Shahid Orthopedic Centre \\ ${ }^{2}$ Assistant Professor orthopedic Surgery, Victoria Hospital Bahawalpur/Shahid Orthopedic Centre \\ ${ }^{3}$ Senior Registrar/ Victoria Hospital Bahawalpur \\ ${ }^{4}$ Woman Medical Office/ Victoria Hospital Bahawalpur/ Shahid Orthopedic Centre \\ ${ }^{5}$ House Officer/ Victoria Hospital Bahawalpur/ Shahid Orthopedic Centre \\ ${ }^{6}$ Senior Registrar/ Victoria Hospital Bahawalpur \\ Corresponding author: Dr Muhammad Khizer Hayat Makki, Email: makkikhizer@hotmail.com, Cell: +923336142389
}

\begin{abstract}
Objective: The aim of this study is to determine the effectiveness of arthoscopy in knee osteoarthritis treatment. Study Design: Prospective study

Place and Duration: Conducted at Victoria hospital Bahawalpur/Civil (sadiq Abbasi) hospital Bahawalpur, during from June 2019 to June 2021.

Methods: There were 70 patients of both genders suffering from knee osteoarthritis presented in this study. Patients were aged between 25-80 years of age. Detailed demographics of enrolled cases age, sex, body mass index and weight were calculated after taking informed written consent. Kellgren Lawrence scale was used for grading of osteoarthritis. MRI and plain X-ray was done among cases. Post-operatively Lysholm score was used to diagnosed outcomes. Patients were followed for 24 months. Complete data was analyzed by SPSS 24.0 version.

Results: Majority of the patients were females $40(57.1 \%)$ and $30(42.9 \%)$ were males. Mean age of the patients was $51.41 \pm 7.44$ years with mean BMI $32.18 \pm 9.31 \mathrm{~kg} / \mathrm{m}^{2}$. Mean weight of the patients was $93.17 \pm 5.64 \mathrm{~kg}$ with mean height $169.9 \pm 5.68 \mathrm{~cm}$. We found that $30(42.9 \%)$ had left knee, $26(37.1 \%)$ patients had right knee and 14 (20\%) had bilateral. According to Kellgren Lawrence scale $40(57.1 \%)$ patients had grade 2, 22 (31.4\%) cases had grade 3 and 8 (11.4\%) cases had grade 4 osteoarthritis. Most common symptom was pain among 69 (98.6\%) cases followed by swelling 50 (71.4\%). According to Lysholm score 36 (51.4\%) cases showed good results with score after complete follow up $80.73 \pm 7.54$. Overall maximum improvement of pain relief among grade 2 osteoarthritis was seen in $28(70 \%)$ cases.

Conclusion: We found in this study that arthoscopy for in knee osteaoarthritis resulted in symptomatic improvement among patients of low grade osteoarthritis where it gives pain alleviation. This arthroscopic therapy regimen can enhance function and activity levels in patients with moderate to severe osteoarthritis.

Keywords: Arthoscopy, Knee osteoarthritis, Pain, Lysholm score, Kellgren Lawrence scale
\end{abstract}

\section{INTRODUCTION}

The pathological changes that occur in joints due to osteoarthritis lead to joint failure. It is estimated that between 22 and $39 \%$ people suffer from osteoarthritis, the most common joint disease [2-4]. Osteoarthritis is the most common cause of immobility in the elderly [4]. Knee osteoarthritis can be treated with a wide range of options. In addition to high tibial osteotomy, other treatment options include distal femoral osteotomy and arthrodesis as well as arthroscopy, bone grafts, or chondrocyte transplantation. The patient's age, activity level, disease severity, and the number of knee compartments affected are all taken into account when selecting a treatment modality [5].

The usefulness of arthroscopy in treating degenerative knee disease has recently been called into question. Total knee replacement has a predictable outcome in patients with advanced osteoarthritis of the knee, but patients who wish to maintain a higher level of activity tend to avoid total knee replacement. Total knee replacement. In light of the increased risk of morbidity and shorter joint replacement lifespan, total knee replacement may not be the best option for everyone. Open procedures take longer to recover from than arthroscopic procedures [6].
It's been proven in numerous studies that arthroscopic techniques like lavage, debridement and abrasion arthroplasty are effective in treating knee osteoarthritis. arthroscopic lavage likely removes cartilaginous debris and inflammatory factors, explaining why patients report relief from their symptoms. Numerous studies suggest that arthroscopic debridement is beneficial in the treatment of knee osteoarthritis. The success rate of arthroscopic debridement is around $70 \%$, and compared to lavage, the debridement's beneficial effect lasts longer. When conservative treatment options have failed in active older adults with mild to moderate osteoarthritis of the knee, arthroscopic debridement is a viable alternative [5].

There is insufficient scientific evidence to support the efficacy of arthroscopic surgery for osteoarthritis of the knee [7]. A large, randomised, controlled study published in the literature found no benefit to surgery [8]. There have been questions raised about the study's methods, however [9], and the authors' conclusion that arthroscopic surgery is ineffective for treating mild to moderate osteoarthritis of the knee has not been widely accepted $[10-11] \ldots$ This means that it's still widely used today [12].

We presented this study is to determine the effectiveness of arthoscopy in knee osteoarthritis treatment. 


\section{MATERIAL AND METHODS}

This prospective study was conducted at Victoria hospital Bahawalpur/Civil (sadiq Abbasi) hospital Bahawalpur, during from June 2019 to June 2021 and comprised of 70 patients. Detailed demographics of enrolled cases were calculated after taking informed written consent. Patients with secondary osteoarthritis, uncertain diagnosis and those did not give any written consent were excluded from this study.

Patients were aged 25-80 years had knee osteoarthritis were presented. All patients had a plain X-ray of the knee joint taken in two orthogonal views (AP weight bearing and Lateral at 30 degrees flexion). The Kellgren Lawrence Scale was used to grade knee osteoarthritis. It was done with the patients lying face down, abducted and rotated externally with their knees bent at 90 degrees. During the operation, tourniquet was commonly used. Antero-lateral as well as antero-medial portals were utilized. The next step was to do a routine diagnostic arthroscopy. On the trochlea and meniscus were seen their individual aspects.

As part of the current study, the debridement process included thorough washing with normal saline solution, the removal of any loose bodies or cartilage flaps, and the removal of any frayed meniscal or articular edges. The Noyes - Stabler approach was used to grade articular cartilage deterioration intraoperatively. Only the following day was authorized for the patient to walk without any assistance, even though he was still wearing his cast. After dressing on the second post-operative day, she was discharged. On the third post-operative day, the bandage covering Jone's wound was removed. On the eleventh post-operative day, the patient requested that the suture be removed in the OPD, and the request was granted. Exercises for the knee quadriceps and hamstrings were recommended to patients. During the 12 week, 6 month, 1 year and 2 year post-operative follow-up visits in OPD, patient's pain severity was assessed. Post-operatively Lysholm score was used to diagnosed outcomes. Patients were followed for 24 months. Complete data was analyzed by SPSS 24.0 version. Frequency and percentage was used for categorical variables.

\section{RESULTS}

Majority of the patients were females 40 (57.1\%) and 30 $(42.9 \%)$ were males. Mean age of the patients was $51.41 \pm 7.44$ years with mean BMI $32.18 \pm 9.31 \mathrm{~kg} / \mathrm{m}^{2}$. Mean weight of the patients was $93.17 \pm 5.64 \mathrm{~kg}$ with mean height $169.9 \pm 5.68 \mathrm{~cm}$. We found that $30(42.9 \%)$ had left knee, 26 (37.1\%) patients had right knee and $14(20 \%)$ had bilateral. According to Kellgren Lawrence scale 40 (57.1\%) patients had grade 2, 22 (31.4\%) cases had grade 3 and $8(11.4 \%)$ cases had grade 4 osteoarthritis.(table 1 )

Table 1: Baseline detailed demographics of enrolled cases

\begin{tabular}{|l|l|l|}
\hline Variables & Frequency $(\mathrm{n}=90)$ & Percentage \\
\hline Gender & 40 & 57.1 \\
\hline Male & 30 & 42.9 \\
\hline Female & $51.41 \pm 7.44$ & \\
\hline Mean age (years) & $32.18 \pm 9.31$ & \\
\hline Mean BMI $\left(\mathrm{kg} / \mathrm{m}^{2}\right)$ & $93.17 \pm 5.64$ & \\
\hline Mean weight $(\mathrm{kg})$ & \multicolumn{2}{|l|}{} \\
\hline
\end{tabular}

\begin{tabular}{|l|l|l|} 
Mean Height $(\mathrm{cm})$ & $169.9 \pm 5.68$ & \\
\hline Type of knee & 30 & 42.9 \\
\hline Left & 26 & 37.1 \\
\hline Right & 14 & 20 \\
\hline Bilateral & 40 & 57.1 \\
\hline Kellgren Lawrence scale & 31.4 \\
\hline Grade 2 & 22 & 11.4 \\
\hline Grade 3 & 8 & \\
\hline Grade 4
\end{tabular}

Most common symptom was pain among 69 (98.6\%) cases followed by swelling 50 (71.4\%), joint effusion in 26 (37.1\%) and bony crepitus found in 23 (32.9\%).(table 2$)$

Table 2: Prevalence of symptoms among enrolled cases

\begin{tabular}{|l|l|l|}
\hline Variables & Frequency & Percentage \\
\hline Symptoms & 69 & 98.6 \\
\hline Pain & 50 & 71.4 \\
\hline Swelling & 26 & 37.1 \\
\hline Joint Effusion & 23 & 32.9 \\
\hline Bony crepitus & 23 & \\
\hline
\end{tabular}

Mean Lysholm score after 2 years was $80.73 \pm 7.54$, $36(51.4 \%)$ cases showed good results, 22 (31.4\%) cases showed fair and $12(17.1 \%)$ presented poor results.(table 3)

Table 3: Post- operative outcomes according to Lysholm score

\begin{tabular}{|l|l|l|}
\hline Variables & Frequency $(\mathrm{n}=70)$ & Percentage \\
\hline Lysholm score & $80.73 \pm 7.54$ & \\
\hline Good & 36 & 51.4 \\
\hline Fair & 22 & 31.4 \\
\hline Poor & 12 & 17.1 \\
\hline Total & 70 & 100 \\
\hline
\end{tabular}

Overall maximum improvement of pain relief among grade 2 osteoarthritis was seen in $28(70 \%)$ cases followed by grade 3 in $8(36.4 \%)$ and 1 (12.5\%). (table 4$)$

Table 4: Post-operative pain relief among cases according to Kellgren Lawrence scale

\begin{tabular}{|l|l|l|}
\hline Pain Relief & Frequency & Percentage \\
\hline Grade 2 $(\mathrm{n}=40)$ & 28 & 70 \\
\hline Yes & 12 & 30 \\
\hline No & 8 & 36.4 \\
\hline Grade 3 $(\mathrm{n}=22)$ & 14 & 63.6 \\
\hline Yes & \multicolumn{2}{|l|}{} \\
\hline No & 1 & 12.5 \\
\hline Grade 4 $(\mathrm{n}=8)$ & 7 & 87.5 \\
\hline Yes & 7 \\
\hline No &
\end{tabular}

\section{DISCUSSION}

Arthritis degenerative is the most common disease in the elderly. Osteoarthritis of the knee is more likely than OA of any other joint to cause impairment. Meniscal tears, loose bodies, osteophytes, synovitis, joint effusion, and limited motion due to contractors are all symptoms of osteoarthritis (OA). OA of the knee is also characterized by the presence of loose fragments of articular cartilage and debris, as well as denuding of the subchondral bone and loose bodies. OA of the knee joint can be managed with a wide range of therapeutic methods. Joint replacement, arthroscopic joint debridement, joint lavage, and analgesics have all been 
recommended as treatment options. Damaged cartilage, synovial membrane, or ligaments within the joint are excised during debridement operations. By removing tissue debris during the debridement operation, the source of synovial tissue irritation is reduced, which in turn reduces symptoms. [13]

In this prospective study 70 patients with ages $25-80$ years presented. Majority of the patients 57.1 were females and rest of the patients $42.9 \%$ were females. Mean weight of the patients was $93.17 \pm 5.64 \mathrm{~kg}$ with mean height $169.9 \pm 5.68 \mathrm{~cm}$. We found that $30(42.9 \%)$ had left knee, 26 (37.1\%) patients had right knee and 14 (20\%) had bilateral. These findings were comparable to the previous some studies.[14,15] The ailment known as knee osteoarthritis affects more than $10 \%$ of people over the age of 60 . Knee arthroscopy has long been used to treat osteoarthritis (OA) of the knee.[16] Mean weight of the patients was $93.17 \pm 5.64 \mathrm{~kg}$ with mean height $169.9 \pm 5.68 \mathrm{~cm}$. According to Kellgren Lawrence scale $40(57.1 \%)$ patients had grade 2, $22(31.4 \%)$ cases had grade 3 and 8 (11.4\%) cases had grade 4 osteoarthritis. Different previous researches presented the same results to our study.[17]

In current study most common symptom was pain among 69 (98.6\%) cases followed by swelling 50 (71.4\%), joint effusion in $26(37.1 \%)$ and bony crepitus found in 23 (32.9\%).[18] Mean Lysholm score after 2 years was $80.73 \pm 7.54,36(51.4 \%)$ cases showed good results, 22 $(31.4 \%)$ cases showed fair and $12(17.1 \%)$ presented poor results. For osteoarthritis of the medial knee compartment, Midori $\mathrm{O}$ et al. found that $79 \%$ of patients were satisfied with their results following an arthroscopic partial medial meniscectomy of the torn posterior horn.[18] 75 percent of patients with loose chondral flaps who underwent debridement or cartilage contouring had excellent to good outcomes. In their study, Figueroa D et al. [19] found that in patients with unstable chondral lesions, 84.61 percent had excellent to good outcomes. Serious Outerbridge grade 4 chondral lesions were linked to poor outcome in our research, and this conclusion was supported by that of Steadman JR et al.[6] In our study over all $82.8 \%$ cases showed effectiveness.

Overall maximum improvement of pain relief among grade 2 osteoarthritis was seen in $28(70 \%)$ cases followed by grade 3 in $8(36.4 \%)$ and 1 (12.5\%). The reason for this is that patients with less severe grade 2 disease have mild degenerative changes and less inflammatory reaction, whereas patients with more severe grade 4 disease have irreversible degenerative changes and have a distorted mechanical axis and thus do not show any improvement at all. These results were comparable to the previous studies.[20,21] Orthoarthritis of the knee is a prevalent cause of locomotor impairment in the aged population. Patient's can be discharged from the hospital within a week of hospitalization if they have undergone arthroscopic therapy for their knee osteoarthritis.

\section{CONCLUSION}

We found in this study that arthoscopy for in knee osteaoarthritis resulted in symptomatic improvement among patients of low grade osteoarthritis where it gives pain alleviation. This arthroscopic therapy regimen can enhance function and activity levels in patients with moderate to severe osteoarthritis.

\section{REFERENCE}

1. Felson DT. Harrison's principles of internal medicine. 17th edition. Vol. 2. USA: McGraw-Hill Companies; 2008. Osteoarthritis, In: Fauci AS, Braunwald E, Kasper DL, Hauser ST, Longo DL, Jameson JL, et al; pp. 2158-65.

2. Chopra A, Patil J, Bilampelly V. The Bhigwan COPCORD: Methodology and first information report APLAR. J Rheumatol. 1997:1:145-54.

3. Chopra A, Patil J, Bilampelly V, Relwane J, Tandle HS. Prevalence of rheumatic disease in rural population in Western India: A WHO-ILARCOPCORD study. J Assoc Physicians India. 2001;49:240-46.

4. Mahajan A, Jasrotia DS, Manhas AS, Jamwal SS. Prevalence of major rheumatic disorders in Jammu. JK Science. 2003;5:63-66.

5. Daboy GD. Campbell's operative orthopedics. 11th edition. Vol. 1 Philadelphia: Mosby Elsevier; 2008. Miscellaneous nontraumatic disorder, In: Canale ST, Beaty JH; pp. 999-1002.

6. Steadman JR, Ramappa AJ, Maxwell RB, Briggs KK. An Arthroscopic Treatment Regimen for Osteoarthritis of the Knee. Arthroscopy. 2007;23(9):948-55.

7. Felson DT, Buckwalter J. Débridement and lavage for osteoarthritis of the knee. N Engl J Med 2002;347:132-133

8. Gillespie WJ. Arthroscopic surgery was not effective for relieving pain or improving function in osteoarthritis of the knee. ACP $J$ Club 2003;138:49-49

9. Morse LJ. Arthroscopic surgery for osteoarthritis of the knee. N Engl J Med 2002;347:1718-1718

10. Chambers KG, Schulzer M. Arthroscopic surgery for osteoarthritis of the knee. N Engl J Med 2002;347:1718-1718

11. Ewing W, Ewing JW. Arthroscopic surgery for osteoarthritis of the knee. N Engl J Med 2002;347:1717-1717

12. Siparsky P, Ryzewicz M, Peterson B, Bartz R. Arthroscopic treatment of osteoarthritis of the knee: are there any evidence-based indications? Clin Orthop Relat Res 2007;455:107-112

13. Hunt SA, Jazrawi LM, Sherman OH. Arthroscopic management of osteoarthritis of the knee. J Am Acad Orthop Surg. 2002;10(5):356363.

14. Dr Md. Azfar Nawaz, Dr Ajay Kumar Mahto. Role of Arthroscopy in Osteoarthritis of Knee Joint. MSCR Volume 08 Issue 09 September 2020

15. Giri S, Santosha, Singh ChA, et al. Role of Arthroscopy in the Treatment of Osteoarthritis of Knee.J Clin Diagn Res. 2015;9(8):RC08-RC11.

16. Figueroa D, Calvo $R$, Vaisman A, Melean P, Villalon I, Figueroa $F$ Clinical Outcomes after Arthroscopic Treatment of Knee Osteoarthritis. The Journal of Arthroscopic and Related Surgery. May 2011;27:45-46.

17. Xiangzheng Su, M.D., Chunbao Li, M.D., Weixiong Liao, M.D. Jianheng Liu, M.D., Hao Zhang, M.D., Ji Li, M.D., and Zhongli Li, M.D. Comparison of Arthroscopic and Conservative Treatments for Knee Osteoarthritis: A 5-Year Retrospective Comparative Study. The Journal of Arthroscopic and Related Surgery, Vol 34, No 3 (March), 2018: pp 652-659

18. Wetterholm M, Turkiewicz A, Stigmar K, Hubertsson J, Englund M The rate of joint replacement in osteoarthritis depends on the patient's socioeconomic status. Acta Orthop 2016;87:245-251.

19. Midori O, Kazuaki Y, Akira K, Toshiyuki T, Satsuki O, Shuji O. Arthroscopic study of the torn posterior horn of medial meniscus for osteoarthritis of the medial compartment of the knee. Arthroscopy. 2002;27:173-76

20. Figueroa D, Calvo R, Vaisman A, Melean P, Villalon I, Figueroa F. Clinical Outcomes after Arthroscopic Treatment of Knee Osteoarthritis. The Journal of Arthroscopic and Related Surgery. May 2011;27:45-46

21. Chen W, Li J, Zhang YZ. Interpretation of American Academy of Orthopaedic Surgeons Clinical Practice Guideline on the treatment of pediatric diaphyseal femur fractures. Zhonghua Wai $\mathrm{Ke} \mathrm{Za} Z \mathrm{Zhi}$ 2017;55:44-48 [in Chinese].

22. Harris JD, Brand JC, Cote MP, Faucett SC, Dhawan A. Research pearls: The significance of statistics and perils of pooling. Part 1: Clinical versus statistical significance. Arthroscopy 2017;33:11021112 